\title{
Customer Lifetime Value to managing marketing strategies in the financial services
}

\author{
Mohammad Safari \\ Faculty of Management, University of Tehran, Tehran, Iran \\ E-mail address m.safari@ut.ac.ir
}

\begin{abstract}
The more a marketing paradigm evolves, the more long-term relationship with customers gains its importance. Nowadays most of corporations and firms in the world, including manufacturers and servicers, increasingly gain their incomes and profits through constructing and maintaining long-term relationship with customers. The move towards a customer-centered approach to marketing, coupled with the increasing availability of customer transaction data, has led to an interest in understanding and estimating customer lifetime value (CLV). Furthermore as marketing endeavors to be more accountable, the need of tools and models for measuring and evaluating efforts and investments that accomplish in marketing extent, is felt. In the other hand strategic planning and management is one of the vital issues of the present organizational context. In this paper the position of CLV in the marketing strategies and strategic planning and management, are recognized. Also based on this study a new conceptual model for the position of CLV in Strategic marketing Planning will be presented. The applied and theoretical recommendations in the end of the paper will be presented.
\end{abstract}

Keywords: Customer Lifetime Value; Customer Relationship Management; strategic Planning and Management; banking sector

\section{INTRODUCTION}

It is over two hundred years since Adam Smith began his "Inquiry into the Nature and Causes of the Wealth of Nations". The field of strategic management is barely fifty years old and it struggles to answer for the business organization the analogous question that smith posed (and for which he provided primitive but remarkably insightful answers) with respect to the nation state. The question (namely, what explains the ability of the business enterprise to generate wealth for the stockholders and other stakeholders) animates managers, policy makers, investors, and the public. Indeed, Strategic management is about the major decisions and investments needed to achieve the goals of the enterprise: taking actions and making investments to reflect opportunities and changing circumstances.

These decisions are the most complex and the most important facing the enterprise. Complexity enters not just because of interdependencies, but also because of uncertainty about customer reaction, competitor response, and market and technological change. Also, as modern economies become predominantly service-based, companies increasingly derive revenue from the creation and sustenance of long-term relationships with their customers. In such an environment, marketing serves the purpose of maximizing customer lifetime value (CLV) and customer equity, which is the sum of the lifetime values of the company's customers. 
Customer lifetime value (CLV) is gaining increasing importance as a marketing metric in both academia and practice (Safari et al, 2014).

The main purpose of this research is: determine the position of customer lifetime value (CLV) in the strategic planning and management process. By clearing this, decision makers and professionals of the field in the one hand and academicians of the area in the other hand can take better decisions and facilitate the higher quality researches in the field of study. In the strategic management process the, customers and marketing department and activities have a much important value.

For meet the goals and objectives of the organization and gain appropriate profit and also satisfy the shareholder mangers and decision makers should determine the value of the customers at individual and group forms. In this study we focus on the CLV and by means of expert's discretion and literature review in detail, the research model that is useful framework for determine the position of customer lifetime value on the strategic management and planning especially in constructing marketing strategies will identified and presented.

\section{STRATEGIC PLANNING AND MANAGEMENT}

The global economic landscape and business world are changing rapidly. Strategic management in turbulent conditions needs to be pro-active. Just when managers think they have developed a strategy for future success, a new technology, process, competitor or customer behavioral pattern emerges. While a sharp focus and "sticking to the knitting" is sometimes the key to success in more stable conditions, the turbulent, knowledge-driven markets of today require dynamic new strategic management approaches and tools. In today's highly competitive business environment, budget-oriented planning or forecast-based planning methods are insufficient for a large corporation to survive and prosper. The firm must engage in strategic planning that clearly defines objectives and assesses both the internal and external situation to formulate strategy, implement the strategy, evaluate the progress, and make adjustments as necessary to stay on track (Wheelen \& Hunger, 1995).

\section{Mission and Objectives}

The mission statement describes the company's business vision, including the unchanging values and purpose of the firm and forward-looking visionary goals that guide the pursuit of future opportunities. Guided by the business vision, the firm's leaders can define measurable financial and strategic objectives. Financial objectives involve measures such as sales targets and earnings growth. Strategic objectives are related to the firm's business position, and may include measures such as market share and reputation (Yuksel \& Dagdeviren, 2007).

\section{Environmental Scanning}

The environmental scan includes the following components:

- Internal analysis of the firm

- Analysis of the firm's industry (task environment)

- External macroenvironment

The internal analysis can identify the firm's strengths and weaknesses and the external analysis reveals opportunities and threats. A profile of the strengths, weaknesses, opportunities, and threats is generated by means of a SWOT analysis. An industry analysis can be performed 
using a framework developed by Michael Porter known as Porter's five forces. This framework evaluates entry barriers, suppliers, customers, substitute products, and industry rivalry.

\section{Strategy Formulation}

Given the information from the environmental scan, the firm should match its strengths to the opportunities that it has identified, while addressing its weaknesses and external threats. To attain superior profitability, the firm seeks to develop a competitive advantage over its rivals. A competitive advantage can be based on cost or differentiation. Michael Porter identified three industry-independent generic strategies from which the firm can choose.

\section{Strategy Implementation}

The selected strategy is implemented by means of programs, budgets, and procedures. Implementation involves organization of the firm's resources and motivation of the staff to achieve objectives. The way in which the strategy is implemented can have a significant impact on whether it will be successful. In a large company, those who implement the strategy likely will be different people from those who formulated it. For this reason, care must be taken to communicate the strategy and the reasoning behind it. Otherwise, the implementation might not succeed if the strategy is misunderstood or if lower-level managers resist its implementation because they do not understand why the particular strategy was selected (Kangas et al, 2003).

\section{Evaluation \& Control}

The implementation of the strategy must be monitored and adjustments made as needed. Evaluation and control consists of the following steps:

- Define parameters to be measured

- Define target values for those parameters

- Perform measurements

- Compare measured results to the pre-defined standard

- Make necessary changes

The strategy literature has long proposed that firms' competitive business strategies must suit their environmental circumstances (Child, 1997). Such strategies focus on how firms compete with, and position themselves in relation to competitors (Fuchs et al, 2000; Langfield-Smith, 2007). The Western literatures have proposed a number of typologies for classifying firm-level competitive strategies (Miles \& Snow, 1978; Porter, 1980). Firms' strategies can be placed on a growth continuum.

At one end are firms following a "pure build" strategy that focuses on attaining growth by improving market share and competitive position at the expense of short- term performance. At the other end are firms following a "pure harvest" strategy, with a focus on maximizing short-term profit and cash flow rather than growth and market share. In the middle are firms that seek to hold their current positions or divest away peripheral operations (Damon et al, 2009).

The challenge for strategic management is to develop frameworks to understand how new levels of order (innovative business models and new industries) emerge, and how one can enable them to emerge from complex, seemingly chaotic patterns of interaction in sociocultural business systems. It is, furthermore, essential to understand the properties (or configurations) of these emergent business models in terms of their resilience to perturbation and their capacity for self-maintenance. 
According to Norman, continuous improvement of an existing business model often becomes a trap from which companies fail to see that the rules of the game are changing faster than the company, or that the game has changed altogether. As stated in the previous chapter, the new strategic management paradigm now becomes systemic strategic management: coshaping of organizational value propositions through systemic organizational capabilities.

The organization's role is now changing from being viewed as a value-providing entity in particular industry value-chains, just "fitting" reactively into value-chain configurations, to being a co-shaping organizer of value creation that may lead to new industry configurations (Leibold et al, 2005).

\section{CUSTOMER LIFETIME VALUE}

Traditional accounting practices focus mainly on measuring tangible assets as a statutory requirement on the balance sheet. However, nowadays it is more usual for intangible assets such as brand, employee and customer relationships to be the critical and often dominant determinants of shareholder value.

A frequently-encountered difficulty for companies wishing to measure customer profitability is that management accounting and reporting systems have tended to reflect product profitability rather than customer profitability. Meanwhile most companies have accounting systems that track costs based on functions (e.g., freight) rather than on a per customer basis (Gupta et al, 2006).

As a result, medium-volume customers tend to be the most profitable. Unfortunately, standard accounting systems focus on periods instead of individual customers or customer groups. To avoid such twists, customers need to be treated as a bundle of cost drivers. This is precisely the principle of Activity-Based Accounting (ABC). It implies that customers are the cause of activities and resources are employed to carry out activities to serve them. Costs are thus allocated on the basis of transactions. ABC therefore provides a fairly accurate means of measuring costs related to customer relationships.

For years, the challenge for businesses could largely be seen as putting in place the means of production to satisfy growing demand, and using marketing techniques to capture customers entering the market (Brooks \& Palmer, 2004). Manufacturers of goods today, however, are competing in a very different environment, and transaction marketing (product, price, place, and promotion, the 4Ps) alone is believed to be insufficient. Instead, relationship marketing is proposed for building more unique relationships with customers and for adding more value to goods and services than what is possible through transaction marketing. Relationship marketing, then, is not only about the 4Ps but also long- term relationships, reflecting a transaction- relationship continuum.

Relationship marketing constitutes a major shift in marketing theory and practice. Rather than focusing on discrete transactions, it emphasizes the establishment, development and maintenance of long-term exchanges. Such relationships are thought to be more profitable than short-term relationships as a result of exchange efficiencies. This is especially true of customer relationships (Reichheld \& Sasser, 2009).

However, since not all customers are financially attractive to the firm, it is crucial that their profitability be determined and that resources be allocated according to the customer lifetime value (CLV).

There are several factors that account for the growing interest in this concept. First, there is an increasing pressure in companies to make marketing accountable. Second, 
financial metrics such as stock price and aggregate profit of the firm or a business unit do not solve the problem either. Although these measures are useful, they have limited diagnostic capability. Third, improvements in information technology have made it easy for firms to collect enormous amount of customer transaction data. This allows firms to use data on revealed preferences rather than intentions.

Customer value has been studied under the name of LTV, Customer Lifetime Value, Customer Equity, and Customer Profitability. The previous researches contain several definitions of CLV. The differences between the definitions are small. Table 1 shows the definitions of CLV. Considering the definitions above, we define CLV as the sum of the revenues gained from company's customers over the lifetime of transactions after the deduction of the total cost of attracting, selling, and servicing customers, taking into account the time value of money.

In other words, CLV is generally defined as the present value of all future profits obtained from a customer over his or her life of relationship with a firm. CLV is similar to the discounted cash flow approach used in finance.

However, there are two key differences. First, CLV is typically defined and estimated at an individual customer or segment level. This allows us to differentiate between customers who are more profitable than others rather than simply examining average profitability. Second, unlike finance, CLV explicitly incorporates the possibility that a customer may defect to competitors in the future.

It is argued that customer relationships are viewed as investment decisions and customers as generators of revenue streams. Customer relationships also generate costs. Hence, in order to measure the customer lifetime value, all revenues and costs pertaining to a customer relationship must be assessed. It is then possible to calculate the current value of cash flow streams. Though, accurately estimating the revenues and costs of a relationship remains a challenging task for a number of reasons:

- Standard accounting does not allow for allocating costs to specific customer relationships.

- Only monetary benefits of customer relationships are taken into account.

- Revenues and costs vary over time.

- Cash flow streams are generated at different points in time and at different levels of risk.

Customer Lifetime Value has been studied under the name of LTV, Customer Value, Customer Equity and Customer Profitability.

The concept is defined as the sum of the revenues gained from company's customers over the lifetime of transactions after deduction of the total cost of attracting, selling and servicing customers, taking into account the time value of money.

The basic formula for calculating CLV for customer $\mathrm{i}$ at time $\mathrm{t}$ for a finite time horizon as follow (Safari-Kahreh et al, 2014):

$$
C L V_{i}=\sum_{t=1}^{T} \frac{\operatorname{Pr} o f i t_{i, t}}{(1+d)^{t}}
$$


Then:

$$
C L V_{i}=\sum_{t=1}^{T} \frac{\text { Revenue }_{i, t}}{(1+d)^{t}}-\sum_{i=1}^{T} \frac{\text { Cost }_{i, t}}{(1+d)^{t}}
$$

Revenue $_{i, t}$ : is revenue that gains from customer $i$ in the time $t$.

Cost $_{i, t}$ : is costs that produce from customer $i$ in the time $t$.

$\mathrm{d}$ : is discount rate (expressed as a decimal or percentage)

$$
\text { PotentialV alue }_{i}=\sum_{j=1}^{n} \operatorname{Pr} o b_{i j} \times \operatorname{Pr} o f i t_{i j}
$$

And we can calculate the total CLV that named CE of customer equity, as follow:

$$
C E=\sum_{i=1}^{I} C L V_{i}
$$

And also we can calculate the CLV by using margins and retention rate of customers, which show as follow:

$$
\begin{aligned}
& C L V=\frac{m r}{(1+i)}+\frac{m r^{2}}{(1+i)^{2}}+\frac{m r^{3}}{(1+i)^{3}}+\ldots=\sum_{t=1}^{\infty} \frac{m \cdot r^{t}}{(1+i)^{t}} \\
& C L V=m \cdot\left(\frac{r}{1+i-r}\right)
\end{aligned}
$$

where the following is true (Safari-Kahreh, 2012):

$m=$ margin or profit from a customer per period

$r=$ retention rate (expressed as a decimal or percentage, e.g., 0.8 or 80 percent)

$i=$ discount rate (expressed as a decimal or percentage, e.g., 0.12 or 12 percent).

The factor to which the margin $(m)$ is multiplied is the margin multiple. This multiple depends on the customer retention rate $(r)$ and the company's discount rate $(i)$. The retention rate depends on product quality, price, customer service, and a host of related marketing activities. For most companies, retention rates are in the range of 60 percent to 90 percent.

\section{METHODOLOGY AND DESIGN}

The method of this research are Applied Research in goal, and in the view point of data gathering is Descriptive-Analytic, non-experimental, that is implemented with the case study format. The case study of this research is Banking Sector of Iran. In this study, by reviewing with experts, the proposed research model will examined and the final research model in the end of the research will presented. For this purpose required data has been gathered from experts using questionnaire. Total of filled questionnaires were 55. The experts of this research are both academicians and professionals of the field. The characteristics of research population including experts are as follow: 
Table 1. Descriptive characteristics of case of the research (Gender).

\begin{tabular}{|c|c|c|}
\hline Variables & Frequency & Percent \\
\hline Gender & 44 & 80 \\
Male & 11 & 20 \\
Female & 38 & 69 \\
Work area & 17 & 31 \\
Academician & 55 & 100 \\
\hline Practitioner & & \\
\hline Total & & \\
\hline
\end{tabular}

\section{1. Validity and Reliability}

Validity and reliability are two necessary features for every measuring material such as questionnaire because these materials should analyze data and provide final conclusions for researchers. To sum up, validity means that a measuring material is used to measure the characteristics.

A questionnaire was used for data collection. Questions were evaluated by the Likert 5choice measurement. Cronbach's Alpha Coefficient was used to measure reliability. The average of Cronbach's alpha for 5 basic elements and categories of this research was 0.92 that is more than the mean acceptable alpha. Hence, the questionnaire was reliable. First, reliability of the questions was evaluated.

Table 2 shows the results (Alpha Cronbach is used to test the reliability of the materials used in the research). All these parts bear high reliability $(\mathrm{a}>0.7)$. Also, validity of this questionnaire, because this instrument was unique and for gathering data was used in this research, was meet by means of experts insights and then examine and analysis of those.

Table 2. Results of Reliability test.

\begin{tabular}{|c|c|c|}
\hline Basic Elements and Categories & $\begin{array}{c}\text { Calculated Cronbach's } \\
\text { Alpha }\end{array}$ & Total of questions \\
\hline customer lifetime value & 0.884 & 6 \\
strategic Formulation & 0.875 & 4 \\
Strategic Implementation & 0.945 & 3 \\
Evaluation and Control & 0.821 & 3 \\
Applicability & 0.905 & 4 \\
\hline Total & 0.92 & 20 \\
\hline
\end{tabular}

\section{ANALYTICAL RESEARCH MODEL}

Based on above descriptions, in this section the research model for presenting the position of customer lifetime value (CLV) in the strategic planning and management process with focus on marketing strategy will show. 


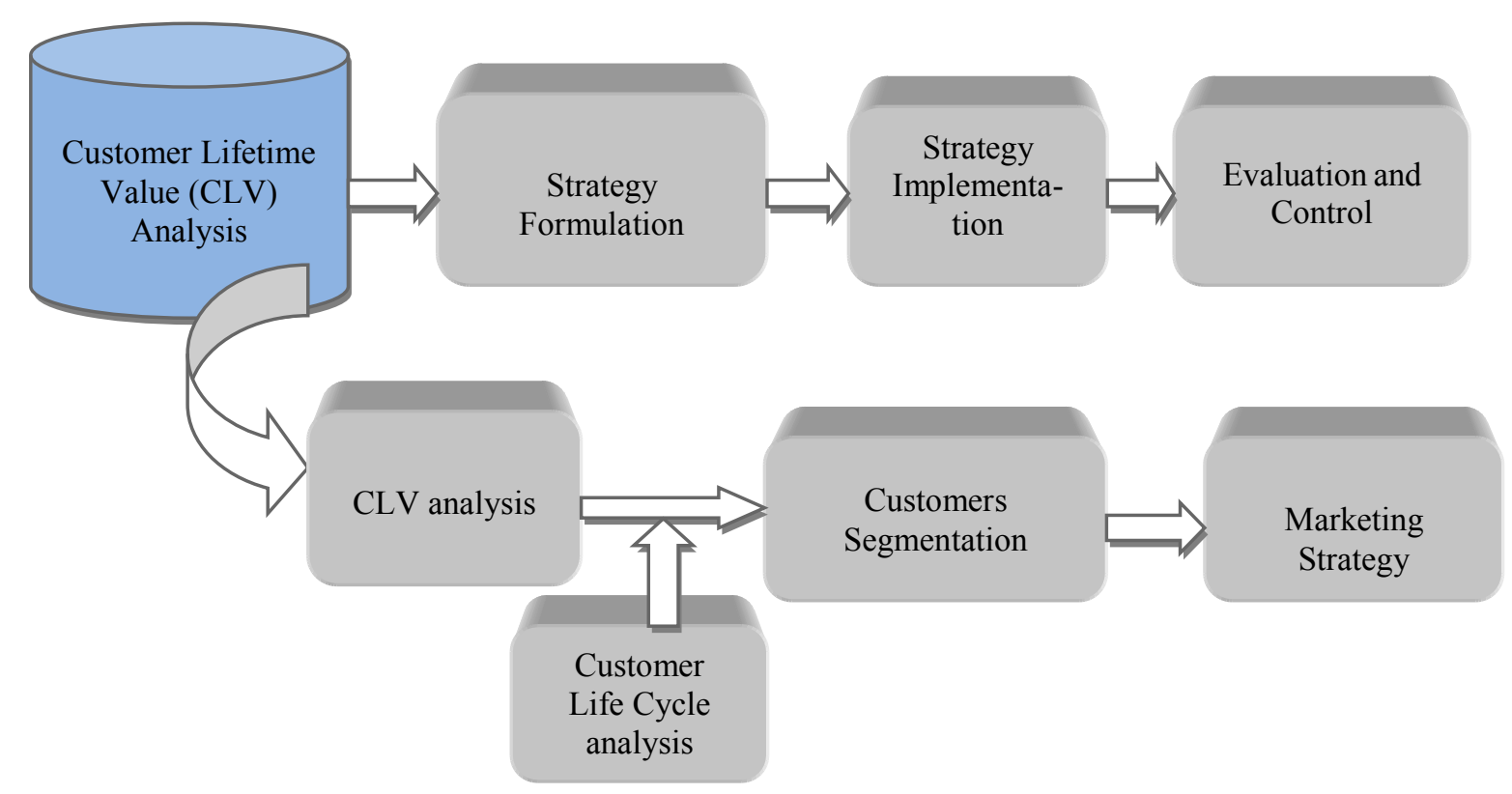

Figure 1. The Analytical Research Model

By analysis the CLV and gathering and then analysis provided datas, strategist of the banks can then segment whole of customers and after that can do better decisions and operations in the field. The main note is that for best mange those customers, policymakers of the banking sector should more attention to the customer lifecycle engineering (CLC). By CLC managers not only can manage the customers but also can constructing the whole of lifecycle of a customer when he or she associated with my business. As businesses shift from a product-centric focus to a customer-centric focus, the customer lifecycle has emerged as a framework to describe the stages - over time - of the relationship between a customer and a business. It starts before a customer becomes a customer - when they are a prospect, and extends through their lifetime as a customer and ends when they become a former customer.

\section{CONCLUSION}

In this research the position of customer lifetime value in the strategic issues especially marketing strategies was investigated and analyzed. The presented research model in this study was unique and much valuable. Indeed, this innovative research presented much insights and directions for decision makers of the banking sector and orientations for the academicians and future researchers of the field. Evidences from this study show that marketing strategies based on CLV are much more effective and successful in the banking sector. By valuable information about lifetime value of customers that will provided by this system mangers and decision makers of the banking sector will could do better decision and operations in the field. If segmentation of the customers was done in the best way strategy formulation and implementation will done in the best. Also, the value of the customer relationship varies across the stages of the lifecycle. Specifically, the value of the customer relationship depends on the revenues received and the costs to service. To initiate the customer revenue stream, the business must first measure the customer lifetime value and 
segment customers based on CLV. After that, managers of the bank can do decisions about each of segments of customers.

\section{References}

[1] Aghaei, M.; Vahedi, E.; Safari-Kahreh, M. \& Pirooz, M. (2014). An Examination of the Relationship between Services Marketing Mix and Brand Equity Dimensions. Procedia-Social and Behavioral Sciences, 109, 865-869.

[2] Aghaie, M.; Vahedi, E.; Asadollahi, A. \& Safari-Kahreh, M. (2014). An empirical investigating to Effects of services marketing mix on Brand Dimensions in Order to enhance brand Equity in the Tehran's Chain Stores. Research Journal of Recent Sciences, 3(2), 43-60.

[3] Ahmadi, P.; Forouzandeh, S. \& Safari Kahreh, M. (2010). The relationship between OCB and Social Exchange Constructs. European Journal of Economics, Finance and Administrative Sciences, 19, 107-120.

[4] Brookes, R. and Palmer, R. A. (2004). The new global marketing reality, Basingstoke' Palgrave.

[5] Child, J. (1997). Strategic choice in the analysis of action, structure, organizations and environment: retrospect and prospect. Organization Studies, 18(1), 43-76.

[6] Damon, M. Fleming; Chee, W. Chow; and Gongmeng, Chen. (2009). Strategy, performance-measurement systems, and performance: A study of Chinese firms. The International Journal of Accounting, No. 3, pp: 23.

[7] Fathollahzadeh, M.; Hashemi, A. \& Safari-Kahreh, M. (2011). Designing a New Model for Determining Customer Value Satisfaction and Loyalty towards Banking Sector of Iran. European Journal of Economics, Finance and Administrative Sciences, 28, 126-138.

[8] Fuchs, P. H., Mifflin, K. E., Miller, D., \& Whitney, J. O. (2000). Strategic integration: competing in the age of capabilities. California Management Review, 42, $118-147$.

[9] Gupta, S.; Hanssens, D.; Hardie, B.; Kahn, W.; Kumar, V.; Lin, N.; Ravishanker, N. \& Sriram, S. (2006). Modeling Customer Lifetime Value. Journal of Service Research, 9 (2), 139-155.

[10] Kamalabadi, N. Bayat, A. Ahmadi, P. Safari-Kahreh, M. (2008). Presentation a new algorithm for performance measurement of Supply chain by using FMADM Approach. World Applied Sciences Journal, 5(5), 582-589.

[11] Kangas, J., Kurtila, M., Kajanus, M., Kangas, A. (2003). Evaluating the management strategies of a forestland estate-the S-O-S approach, Journal of Environmental Management, 69, 349-358.

[12] Kangas, J., Kurtila, M., Kajanus, M., Kangas, A. (2003). Evaluating the management strategies of a forestland estate-the S-O-S approach, Journal of Environmental Management, 69, 349-358. 
[13] Langfield-Smith, K. (2007). A review of quantitative research in management control systems and strategy. In C. S. Chapman, A. G. Hopwood, \& M. D. Shields (Eds.), Handbook of Management Accounting Research, Vol. 1. (pp. 753-784) Oxford, UK: Elsevier.

[14] Leibold M., Probst G., Gibbert M. (2005). Strategic Management in the Knowledge Economy: New Approaches and Business Applications, Wiley publications, Second Edition.

[15] Miles, R. W., \& Snow, C. C. (1978). Organizational Strategy, Structure, and Process. New York: McGraw-Hill.

[16] Porter, M. E. (1980). Competitive Strategy. New York: Free Press.

[17] Reichheld, F. F. and Sasser, E. W. (2009). Zero defections: quality comes to services. Harvard Business Review, 68, 105-111.

[18] Safari-Kahreh, M. \& Safari-Kahreh, Z. (2012). An Empirical Analysis to Design Enhanced Customer Lifetime Value Based on Customer Loyalty: Evidences from Iranian Banking Sector. Iranian Journal of Management Studies, 5(2), 145-167.

[19] Safari-Kahreh, M.; Ahmadi, H. \& Hashemi, A. (2011). Achieving competitive advantage through empowering employees: An empirical study. Far East Journal of Psychology and Business, 3 (3), 26-37.

[20] Safari-Kahreh, M.; Tive, M.; Babania, A. \& Hesan, M. (2014). Analyzing the Applications of Customer Lifetime Value (CLV) based on Benefit Segmentation for the Banking Sector. Procedia-Social and Behavioral Sciences, 109, 590-594.

[21] Safari-Kahreh, Z.; Shirmohammadi, A. \& Safari-Kahreh, M. (2012). An empirical study to analyze customer relationship management strategy using balanced scorecard. Management Science Letters, 2(5), 1603-1612.

[22] Seyed-Javadin S. R., Raei R., Iravani M. J., Safari M. International Letters of Social and Humanistic Sciences 24 (2014) 45-55.

[23] Seyed-Javadin S. R., Raei R., Iravani M. J., Safari M., International Letters of Social and Humanistic Sciences 26 (2014) 46-56.

[24] Seyed-Javadin S. R., Raei R., Iravani M. J. Safari M., International Letters of Social and Humanistic Sciences 28 (2014) 58-66.

[25] Wheelen, T.L., Hunger, J.D. (1995). Strategic Management and Business Policy, Addison-Wesley, Reading, MA.

[26] Yuksel I., Dagdeviren M. (2007). Using the analytic network process (ANP) in a SWOT analysis - a case study for a textile firm. Information Science 177(16) (2007) 3364-3382. 